\title{
Fabrication of a novel hybrid AlMg5/SiC/PLZT metal matrix composite produced by hot extrusion
}

\author{
C. Montalba ${ }^{a, \Uparrow}$, K. Ramam ${ }^{a}{ }^{\Uparrow}$, D.G. Eskin ${ }^{\text {b,c }}$, E.M. Ruiz-Navas ${ }^{\mathrm{d}}$, O. Prat ${ }^{\text {a }}$ \\ ${ }^{a}$ Departamento de Ingeniería de Materiales - DIMAT, Facultad de Ingeniería, Universidad de Concepción, Concepción 4070409, Chile \\ ${ }^{\mathrm{b}}$ Brunel Centre for Advanced Solidification Technology (BCAST), Brunel University, Uxbridge UB8 3PH, UK \\ ${ }^{\mathrm{c}}$ Tomsk State University, Tomsk 634050, Russia \\ d Departamento de Ciencia e Ingeniería de Materiales e Ingeniería Química, Universidad Carlos III de Madrid, 28911 Leganés (Madrid), Spain
}

Keywords:

Hybrid metal matrix composite

Piezoelectric

Damping

Powder metallurgy

Hot extrusion

\begin{abstract}
a b s t r a c t
A novel type of piezoelectric aluminium-based hybrid composite containing silicon carbide (SiC) and piezoelectric lead lanthanum zirconate titanate (PLZT) was prepared using powder metallurgy technique followed by sintering at $630 \cdot \mathrm{C}$ and hot extrusion at $500 \cdot \mathrm{C}$. The volume fraction of PLZT particles varied as $0 \%, 5 \%, 10 \%$ and $15 \%$ with fixed weight 1 wt. $\%$ of SiC respectively in the composite and its effects on the microstructure as well as the damping nature of the composite were studied. The microstructure of composites was analysed by scanning electron microscope (SEM) and electron microprobe, and damping behaviour was investigated using Dynamic Mechanical Analysis (DMA) as function of temperature. Microstructural results attested the homogeneity of two different reinforcements in the composite and thus confirmed hot extrusion process had shown promising route for obtaining homogenous and dense metal matrix composites. DMA studies of homogenous hybrid MMCs indicated that the increase in wt.\% of piezoelectric PLZT particles improved the damping properties.
\end{abstract}

(c) 2015 Elsevier Ltd. All rights reserved.

\section{Introduction}

Hybrid metal matrix composites (HMMCs) are promising and advanced materials for multifunctional, mechanical, medical, industrial and energy applications and progressing as second-generation of composites. The main emphasis of hybrid materials is on combining largely different types, shapes and sizes of reinforcements, to form a single component to advance structures with lower cost and weight [1,2]. Since 1970s, hybrid composites have been investigated in order to meet the demands of industry with high mechanical properties, corrosion resistance, high damage tolerance, etc. [3,4]. Nowadays, technological developments have been performed in order to improve the multi-component hybrid composites field by replacing single reinforced composites with reinforcing structural and/or functional materials with more than one type of reinforcements for advanced applications using improved production routes [5-7]. Aluminium hybrid matrix composite coatings containing $\mathrm{SiC}$ and graphite particles were explored by plasma spraying with good bonding results [8]. Umanath et al. [9] have examined wear behaviour of Al6061-T6 discontinuously reinforced with silicon carbide $(\mathrm{SiC})$ and aluminium oxide $\left(\mathrm{Al}_{2} \mathrm{O}_{3}\right)$

\footnotetext{
$\Uparrow$ Corresponding authors. Tel.: +56 0412203369.

E-mail address: cristomontalba@udec.cl (C. Montalba).
}

composite with significant effect on the wear behaviour. Mechanical and functional properties of composites were investigated by Hu et al. [10] which had shown mechanical properties and damping capacity of $\mathrm{SiC}_{\mathrm{p}} / \mathrm{TiNi}_{\mathrm{f}} / \mathrm{Al}$ composite were based principally on shape memory and damping capacity of TiNi fibres.

Solid solutions of lead zirconate titanate, $\mathrm{Pb}\left(\mathrm{Zr}_{\mathrm{x}} \mathrm{Ti}_{(1-\mathrm{x})}\right) \mathrm{O}_{3}$ (PZT) and its modified compositions are the most useful piezoelectric and ferroelectric materials for applications such as transducers, actuators, high-density energy storage and high-density power output [11,12]. Furthermore, piezoelectric ceramic compounds exhibit elevated constructive vibration damping capacity, which can be attributed to an inelastic strain response of ferroelastic domains to externally applied stress effecting on domain structure orientation [13].

According to literature, hybrid composites reinforced with piezoelectric components were studied exclusively in polymeric matrix $[14,15]$, with optimum damping results. Nevertheless, single reinforced nonferrous matrices composites reinforced with piezoelectric particles were investigated with promising mechanical and functional results as shown in literature, for example, Yoshida et al. [16] researched $\mathrm{Cu}$ matrix reinforced with $\mathrm{PbTiO}_{3}$ which increased three times damping capacity of pure $\mathrm{Cu}$ rods, Kampe et al. [17] explored vibration damping behaviour of barium titanate $\left(\mathrm{BaTiO}_{3}\right)$ in $\mathrm{Cu}-\mathrm{Sn}$ matrix and Zhang et al. [18] have investigated Aluminium $/ \mathrm{BaTiO}_{3}$ matrix produced by hot extrusion. 
The goal of this study was to develop a novel multifunctional hybrid metal matrix composite, discontinuously-reinforced by two ceramic reinforcements, with high damping capacity and elevated stiffness. Accordingly, we have selected structural and functional (electroceramic) reinforcements dispersed in an aluminium alloy.

Matrix selected was Aluminium with 5 wt.\% Magnesium. Reinforcing materials chosen were piezoelectric, PLZT (i.e. $\mathrm{Pb}_{(1-\mathrm{x})} \mathrm{La}_{\mathrm{x}}\left(\mathrm{Zr}_{\mathrm{z}} \mathrm{Ti}_{(1-\mathrm{z})}\right)_{(1-\mathrm{x}) / 4} \mathrm{O}_{3}$ [19], and silicon carbide (i.e. SiC) [20]. HMMCs were produced by hot extrusion with ratios of weight percentage of electroceramic PLZT with $\mathrm{SiC}$ in $\mathrm{Al}$ alloy matrix were varied as 5:1, 10:1 and 15:1. The characterization of composites, produced by hot extrusion, was done by electron microscopy for microstructure analysis, and to study reinforcements distribution and matrix/reinforcement interface. Damping properties for the hybrid metal matrix composites were analysed using Dynamic Mechanical Analysis (DMA).

\section{Experimental procedure}

This section presents fabrication and characterization of multifunctional metal matrix composites reinforced with functional PLZT and structural silicon carbide (SiC) ceramics.

\subsection{Starting materials}

Aluminium alloy 5 wt.\% Mg, 0.25 wt.\% Sn was selected as a metal matrix. Traces of Tin were included exclusively to promote wettability between particles [21]. Reinforcing materials used were tetragonal piezoelectric PLZT $\left[\mathrm{Pb}_{(1-\mathrm{x})} \mathrm{La}_{\mathrm{x}}\left(\mathrm{Zr}_{\mathrm{z}} \mathrm{Ti}_{(1-\mathrm{z})}\right)_{(1-\mathrm{x}) / 4} \mathrm{O}_{3}\right]$ and hexagonal silicon carbide $(\mathrm{SiC})$ ceramic particles. PLZT $\left(\mathrm{Pb}_{0.988} \mathrm{La}_{0.012}\left(\mathrm{Zr}_{0.53} \mathrm{Ti}_{0.47}\right)_{0.997} \mathrm{O}_{3}\right)$ ceramic powder was prepared through solid-state reaction method at $1240 \cdot \mathrm{C}$ for $3 \mathrm{~h}$ in a high purity alumina crucible without protective atmosphere which resulted in ceramic particles ranged around $12 \mathbf{~} \mathbf{m}$ in diameter. Structural reinforcement particles consisted of SiC a-phase, 99.8\% metal basis with 2 Im particle size were obtained from Alfa Aesar Chemicals, USA.

\subsection{Composite materials}

Stoichiometric compositions (Table 1) were mixed by ball milling and cold pressed using a uniaxial hydraulic press and a floating bending strength die in order to obtain green bodies. The weight fraction of SiC was fixed to 1 wt.\% while the PLZT particles in the composite had four different weight fractions: $0 \%, 5 \%, 10 \%$ and $15 \%$. These reinforcement amounts were selected by presuming linear results for all composites.

Before filling the die, the batch powders were mixed with 1.5 wt.\% lubricant Ethylene Bis-Stearamide (EBS) with 40 Im particle size (ACRAWAX-C powder) to facilitate green bodies pressing step. Specimens were compacted at $600 \mathrm{MPa}$ into cylindrical pellets with $25 \mathrm{~mm}$ and $15 \mathrm{~mm}$ in diameter and thickness, respectively.

\section{Table 1}

Composite designation and ratios of wt.\% reinforcements.

\begin{tabular}{ll}
\hline Sample & Material \\
\hline Matrix & Al-5 wt.\% Mg (Sn) \\
SE1 & Al-5 wt.\% Mg/1 wt.\% SiC \\
SE2 & Al alloy/1 wt.\% SiC/5 wt.\% PLZT \\
SE3 & Al alloy/1 wt.\% SiC/10 wt.\% PLZT \\
SE4 & Al alloy/1 wt.\% SiC/15 wt.\% PLZT \\
\hline
\end{tabular}

Green compacts were subjected to a delubrication heat treatment (heating to $400 \cdot \mathrm{C} / 20 \mathrm{~min}$ ) followed by sintering phase at $630 \cdot \mathrm{C} / 45 \mathrm{~min}$. Sintering step was performed in Eurotherm tubular furnace with an extra pure nitrogen protective atmosphere. Sintered samples were extruded at $500 \cdot \mathrm{C}$, without atmospheric protection using an extrusion ratio of $25: 1$ to ensure full density. Before heating to the extrusion temperature, a thin layer of a mixture of graphite and oil was applied to the surfaces of sintered bulks, which is useful as lubricant and an oxidation barrier. Extruded compacts were of $8 \mathrm{~mm}$ and $146 \mathrm{~mm}$ in diameter and length, respectively. After extrusion, rods were air cooled to room temperature. Fig. 1 shows the schematic presentation of composite fabrication; first mixing of reinforcements with matrix, compact of composites, sintering and finally full densification through hot extrusion.

Density measurements were performed following ASTM: B311 test method. Microstructure was observed by means of scanning electron microscope JEOL JSM 6380LV and matrix/reinforcement interface was analysed by Electron microprobe JEOL JXA8600 M. Dynamic Mechanical Analysis (DMA) measurements were carried out in a Perkin Elmer DMA 7e in the temperature range from $20 \cdot \mathrm{C}$ to $400 \cdot \mathrm{C}$ at $1 \mathrm{~Hz}$ frequency. Storage modulus $\left(\mathrm{E}^{0}\right)$ and Tan d were determined for the matrix and composites with the gauge dimension of damping specimens of $1 \mathrm{~mm} \times 3 \mathrm{~mm} \times 22 \mathrm{~mm}$.

\section{Results and discussion}

\subsection{Density for matrix and composites as sintered and extruded}

Density measurements were performed for pre and post extruded samples. Fig. 2 shows the density results of matrix and composites as sintered and extruded. In the case of hybrid metal matrix composites, densification will play vital role due to two reasons. First, dense and compact composites are directly related with the enhancement of mechanical properties. Variables like temperature and protective atmosphere, or post treatment such as extrusion, perform an important role in densification as well improving matrix/reinforcements contact and decreasing porosity.

Finally, the free spaces in the composite can reduce piezoelectric damping enhancement. Feeble bonding between matrix itself (pores), or matrix and reinforcement could be attributed to damping through a sliding friction mechanism [22].

Hence, density is an important factor to study compactability and porosity of composite and explains how extrusion improves it.

Theoretical density was calculated with the rule of mixture (Eq. (1)) [23], where weight fraction and density are denoted by $\mathrm{W}_{\mathrm{x}}$ and $\mathrm{q}_{\mathrm{x}}$, respectively of each component in the hybrid metal matrix composite.

$\mathrm{q}_{\mathrm{t}} 1 / 4 \mathrm{q}_{\text {Matrix }} \times \mathrm{W}_{\text {matrix }} \mathrm{pq}_{\mathrm{SiC}} \times \mathrm{W}_{\text {Sic }} \mathrm{pq}_{\text {PLZT }} \times \mathrm{W}_{\text {PLZT }}$

It could be observed that density increased drastically with increasing functional reinforcement, due to incorporation of high-density PLZT ceramic particles $\left(8 \mathrm{~g} / \mathrm{cm}^{3}\right)$.

For as sintered hybrid composites samples, density remained nearly constant, independent of weight percent of reinforcements. Densification has not been observed in as-sintered composites, probably due to porosity in aluminium matrix or weak wettability in the interface of matrix/reinforcement.

In this study, extruded samples have followed the tendency of theoretical density. With post forming step, composites have improved densification due to diminishing of porosity and voids in the matrix and in the interface with reinforcements.

Porosity of extruded sample was measured by determining density following ASTM: B311 test method and compared with the theoretical value. Results presented in Fig. 2 demonstrated a 


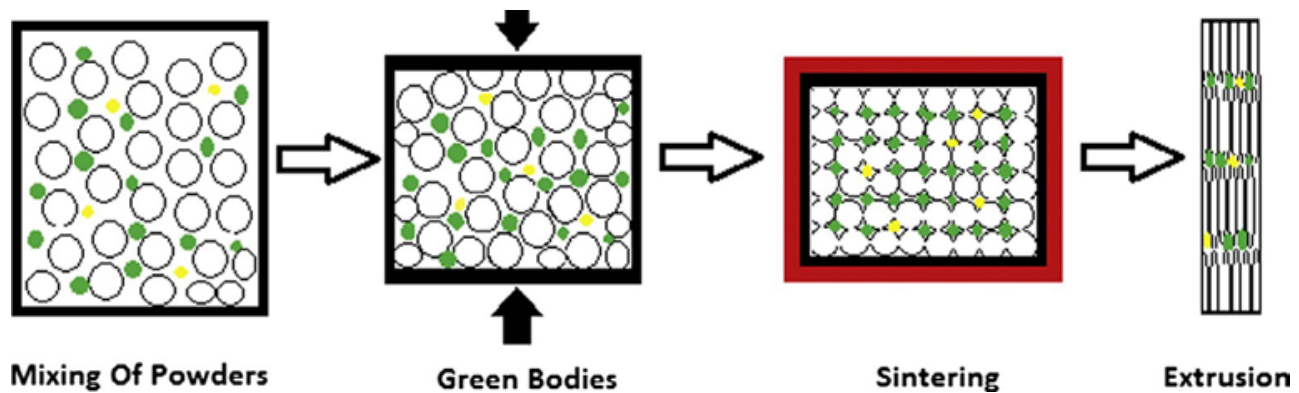

Fig. 1. Sequence of composite production.

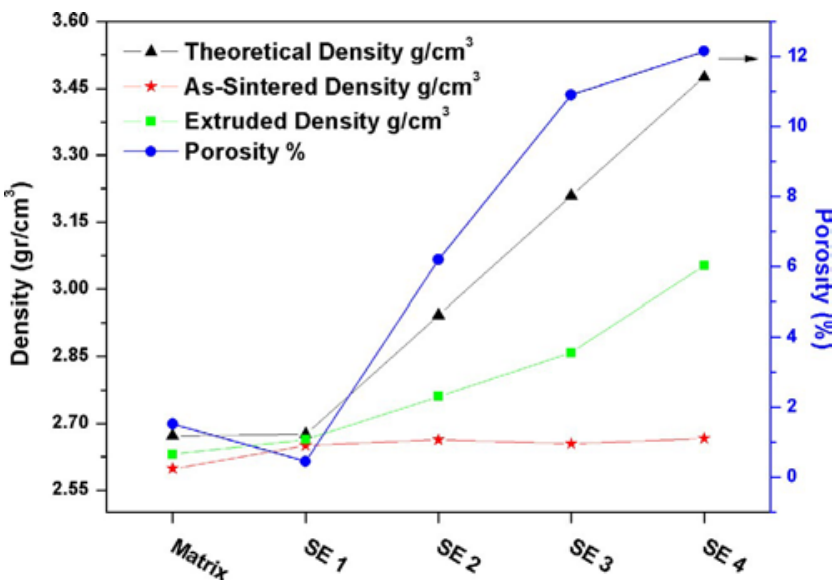

Fig. 2. Density for matrix and composites and porosity of extruded composites.

$1.52 \%$ of pores for matrix extruded, a lower value of porosity for SE1 of $0.46 \%$ and $6.2 \%, 10.9 \%$ and $12.2 \%$ for composites with 5 wt.\%, 10 wt.\% and 15 wt.\% of PLZT, respectively. Generally, porosity is defined as the measurement that gives the fraction of the total volume, which is void. Regarding the high volume of porosity found in composites containing PLZT functional particles, the significant increase in porosity could be attributable to (i) porosity or voids in the metal matrix, (ii) particles/matrix interface free space, and (iii) porosity of polycrystalline particles (SiC and PLZT).

In our study, based on the measured and theoretical densities, post treatment (extrusion) is crucial to obtain fully dense compact composites with superior mechanical properties, and crucial to demonstrate damping mechanism of these novel hybrid metal matrix composites.

\subsection{Microstructural analysis}

Fig. 3 shows scanning electron micrographs (SEM) of extruded $\mathrm{Al} / \mathrm{SiC}_{\mathrm{p}} / \mathrm{PLZT}_{\mathrm{p}}$ composite. The weight fraction of PLZT particles in the four different composites was $0 \%, 5 \%, 10 \%$ and $15 \%$, respectively.

It is clear from the micrograph (Fig. 3(a)) about the homogenous dispersion of $\mathrm{SiC}$ particles. Fig. 3(a-d) reveals discrete porosity in composites pointed with white arrows. Homogenous distribution of functional (PLZT) and structural (SiC) reinforcement particles in aluminium alloy matrix was confirmed with specific agglomeration spots demarked with white circles in the different micrographs.

It is evident from the micrographs that the principal concentration of reinforcement particles was on the grain boundary since it is energetically more stable location. Homogeneous distribution of the reinforcements in the composite is necessary to have uniform mechanical and functional properties [17].
In order to obtain more in detailed information, a higher magnification micrograph of the composite interface is provided in Fig. 4. In this study, interfacial reaction matrix/PLZT was not found in the composite.

From these microscopic studies, PLZT reinforcing particle seems fragmented, confirming the polycrystalline particles nature. Evidence of porosity in the vicinity of the interface was not observed. In this study, microscopy results are supported by density profile in these composites.

Chemical stability was verified by an electron probe micro-analyzer EPMA mapping. Fig. 4(b) presents chemical elemental mapping performed on the functional reinforcement showed Aluminium alloy matrix and the compounds of Lead, Zirconium and Titanium with no evidence of functional reinforcement dissolution into the matrix. Reinforcing particles seems to be more stable than aluminium-magnesium matrix at sintering $\left(630{ }^{\circ} \mathrm{C}\right)$ and extrusion $\left(500{ }^{\circ} \mathrm{C}\right)$ temperatures. Same behaviour was found in other samples with different PLZT wt.\% investigated. These studies provide us to speculate the stability of piezoelectric reinforcement particles with $\mathrm{Al}$ at selected processing conditions by fusion route in our future investigations.

Based on the EPMA studies, elemental line scan was chosen to investigate the interfacial reaction near PLZT particle and matrix in the composite. The change of the chemical compositions in the vicinity of the boundary between the PLZT particle and the matrix is shown in Fig. 4(c). It is clear that an interfacial reaction bonding layer of about $2 \mathbf{I m}$ thick was formed. Main elements reacting in the interfacial layer found were $\mathrm{Al}$ and $\mathrm{Pb}$. According to literature, aluminium and lead have shown immiscibility [24], thus, in our study, no compound has formed by these two elements. Literature studies [24] showed that magnesium inclusion reduces the liquid miscibility gap of Al- $\mathrm{Pb}$ until approximately $25-30 \% \mathrm{Mg}$ on contrary, it disappears at lower concentrations of $\mathrm{Mg}$, however, in our study, matrix has $5 \mathrm{wt} \% \mathrm{Mg}$ and thus, presumably $\mathrm{Al}-\mathrm{Pb}$ miscibility remains constant.

SiC and PLZT interaction was researched by Zeng et al. [25] where XRD studies noted that diffusion of SiC in the piezoelectric compound had no effect on the perovskite structure of the ceramic, thus, in our composite, structure remains intact, i.e. with functional properties.

\subsection{Mechanical vibration properties}

Figs. 5 and 6 presents tangent of the phase angle (Tan d) and the storage modulus $\left(E^{0}\right)$ for matrix and composites at different temperatures between 25 and $400 \cdot$ C. Both parameters were notably affected by the temperature in these composites.

Tan d (Fig. 5) curves remain invariable between room temperature to $100 \cdot \mathrm{C}$, however, above this temperature damping capacities increase with increasing temperature. Independent of constant values under $100 \cdot \mathrm{C}$, an increase of damping capacity values was 

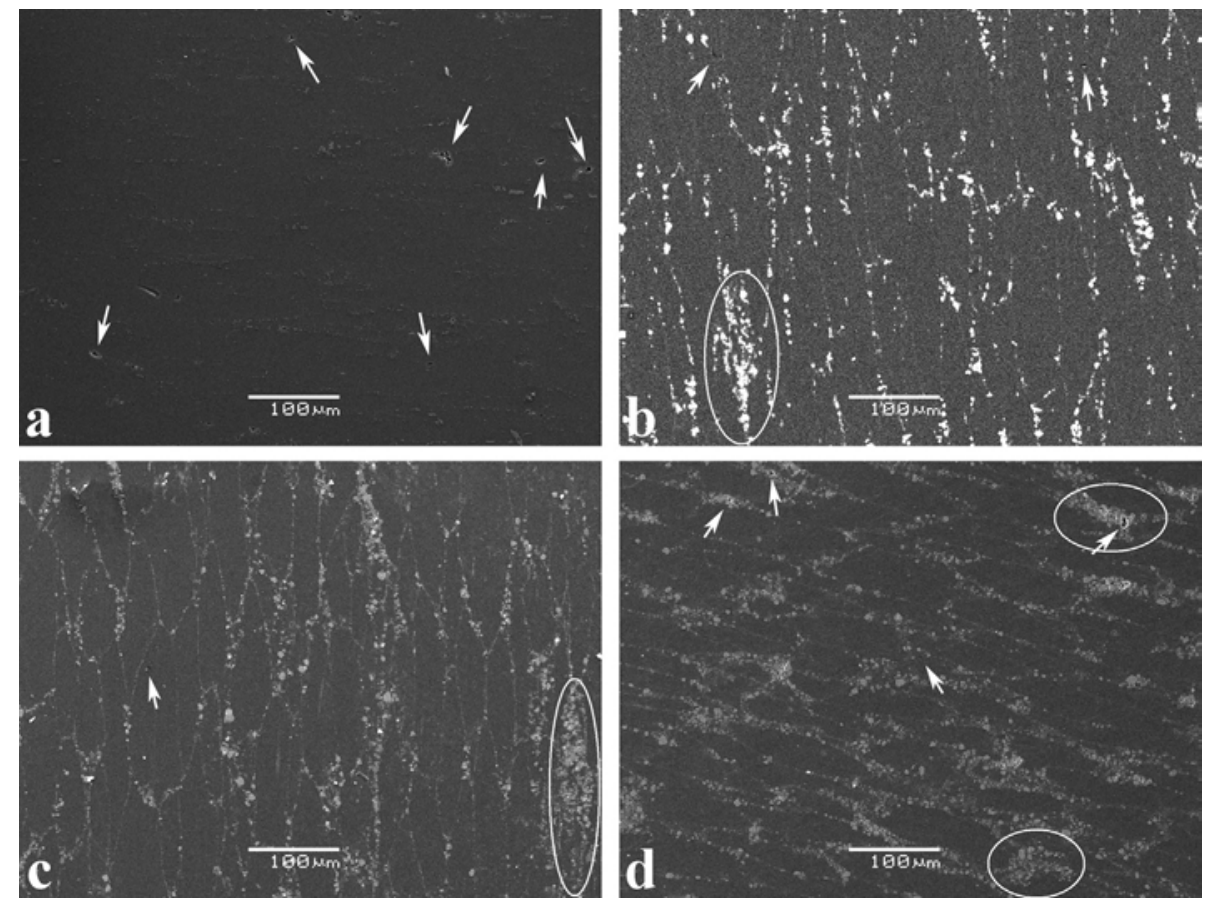

Fig. 3. SEM micrographs of extruded (a) SE1, (b) SE2, (c) SE3 and (d) SE4 composites at 500x of magnification.
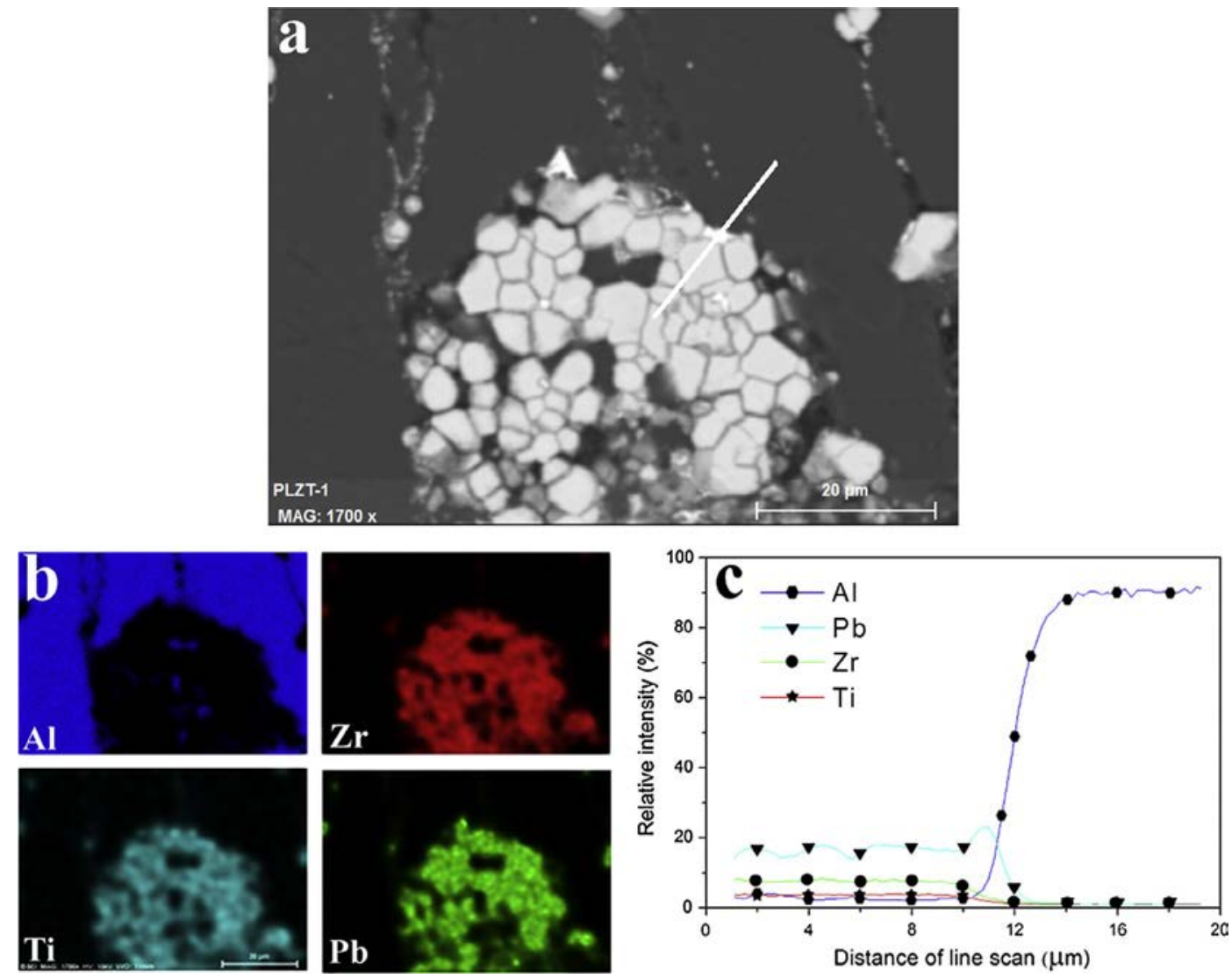

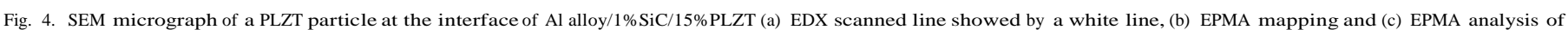
the interface. 


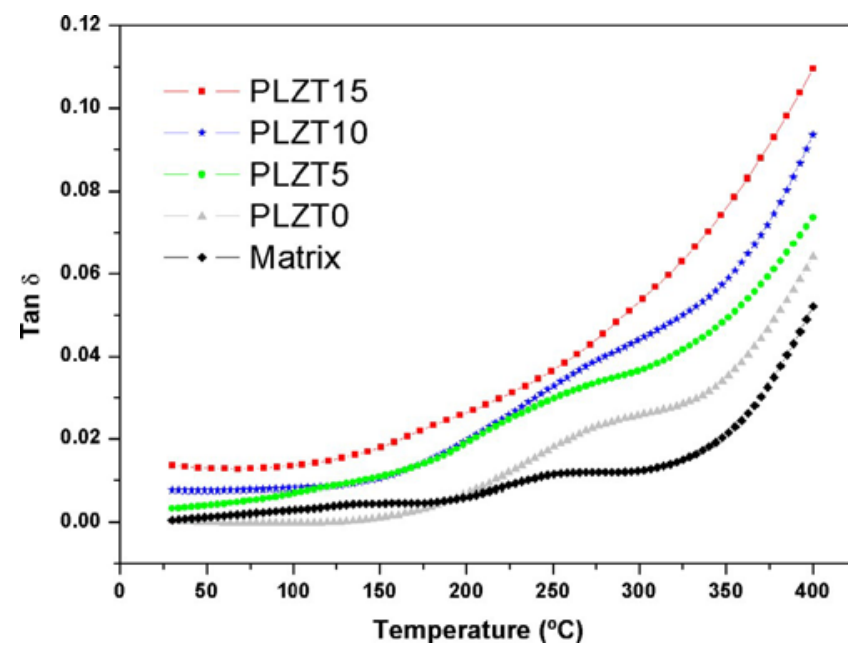

Fig. 5. Tan d versus temperature of (a) Matrix (black color), (b) SE1 (gray color), (c) SE2 (green color), (d) SE3 (blue color) and (e) SE4 (red color). (For interpretation of the references to colours in this figure legend, the reader is referred to the web version of this paper.)

recognized for samples with piezoelectric particles, and increasing weight percentage of piezoelectric particles demonstrate an increase in the value of Tan $\mathrm{d}$.

Damping capacity increment in hybrid composites is principally due to damping capacity of PLZT reinforcement i.e. inelastic strain response [13], also because of grain boundary in the aluminium matrix [26]. Complementary to this damping nature increment, interfaces matrix/reinforcement (or reinforcement ${ }_{\mathrm{x}} /$ reinforce- $^{-}$ ment $_{\mathrm{y}}$ in HMMC) also supported mitigation of the vibration stress in composites [25].

The sample SE 4 shows an increased damping capacity close to 10 times from 0.015 at room temperature to 0.109 at $400 \cdot \mathrm{C}$, indicating that PLZT reinforcing aluminium alloy matrix composite has superior high damping capacities at high temperatures. Same results, compared with literature [18] based on single functional ceramic particle, reaffirm superior vibration and noise suppression for hybrid aluminium metal matrix composite reinforced with structural (SiC) and functional (PLZT) particles.

DMA storage modulus curves of the composite are presented in Fig. 6. A decrease in mechanical properties is observed for all samples. At room temperature, aluminium matrix sample has a storage

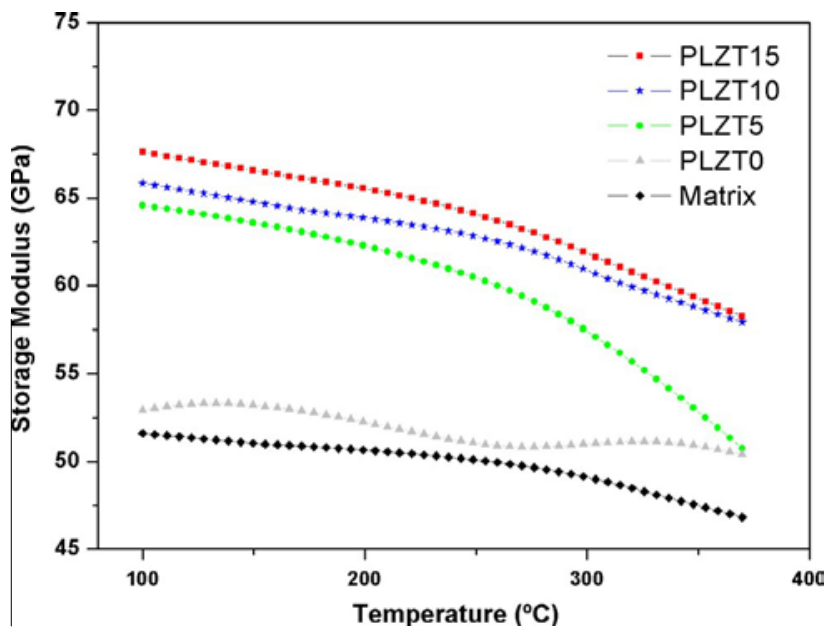

Fig. 6. Storage modulus versus temperature of (a) Matrix (black color), (b) SE1 (gray color), (c) SE2 (green color), (d) SE3 (blue color) and (e) SE4 (red color). (For interpretation of the references to colours in this figure legend, the reader is referred to the web version of this paper.) modulus close to $50 \mathrm{GPa}$ while, at the same temperature, sample reinforced with 15 wt.\% of piezoelectric has $68 \mathrm{GPa}$. This suggests that high mechanical properties could be reached in multifunctional hybrid $\mathrm{AlMg} 5 / \mathrm{PLZT}_{\mathrm{p}} / \mathrm{SiC}_{\mathrm{p}}$ composites.

Composites reinforced with 10 and 15 wt.\% PLZT presents proper thermal stability in the whole temperature range while 5 wt.\% PLZT composite shows an important drop in the storage modulus at $250 \cdot \mathrm{C}$ attributable to inhomogeneous distribution of particles in aluminium-magnesium matrix. Although microstructure analysis shows homogeneous distribution, agglomeration of particles is inevitable and usually occurs at high volume fraction, moreover, a slight percentage of inhomogeneous state could be influenced by processing conditions in the composites.

In essence, storage modulus presented an increase at $370 \cdot \mathrm{C}$ of $28.3 \pm 0.8 \%, 23.9 \pm 0.5 \%$ and $8.7 \pm 0.5 \%$ for samples reinforced with 15, 10 and 5 wt.\% of PLZT compared with matrix.

Piezoelectric PLZT particles have the ability of improve damping capacity of metal matrix without sacrificing mechanical properties [27]. Due to damping capacity of PLZT reinforcement and energy dissipation caused by interfacial sliding in the interface of matrixreinforcements in the whole range of temperatures, these composites are suitable for structural, piezoelectric and frequency dependent applications.

\section{Conclusion}

Extrusion is a high-quality method to produce high-dense, homogenous and excellent interface matrix/reinforcement connection in Hybrid metal matrix composites. The incorporation of functional reinforcing particles into the aluminium matrix promoted damping mechanism which becomes more pronounced with the increasing wt.\% of functional and constant $1 \mathrm{wt} . \% \mathrm{SiC}$ structural reinforcements where higher Tan $d$ value $(0.109)$ was obtained at $400 \cdot C$ for sample with 15 wt.\% PLZT. Storage modulus presented an important increase at $370 \cdot \mathrm{C}$ of $28.3 \pm 0.8 \%$ with 15 wt.\% PLZT compared with unreinforced matrix.

Results confirmed that PLZT and SiC are promising reinforcements for aluminium metal matrix to obtain high damping capacities at an elevated temperature without sacrificing the mechanical strength and stiffness of matrix and composite.

\section{Acknowledgements}

Authors CMW and Koduri Ramam acknowledge and are grateful to CONICYT for Doctoral Research Fellowship and also acknowledge Universidad Carlos III, Spain for hosting internship to carryout doctoral research work and Universidad del Biobío for characterization support. Authors Koduri Ramam and CMW greatly acknowledge Fondecyt Research Project Number 1110583 for the financial support with the research project and characterization equipment.

\section{References}

[1] Ahmadi A, Toroghinejad MR, Najafizadeh A. Evaluation of microstructure and mechanical properties of $\mathrm{Al} / \mathrm{Al} 2 \mathrm{O} / \mathrm{SiC}$ hybrid composite fabricated by accumulative roll bonding process. Mater Des 2014;53:13-9.

[2] Wei ZG, Sandstrom R, Miyazaki S. Shape memory materials and hybrid composites for smart systems: part II shape-memory hybrid composites. J Mater Sci 1998;33:3763-83.

[3] Bowen DV, Ayers KB. A note on the optimisation of aluminium alloy/cfrp laminates. Composites 1975;6:152-6.

[4] Gaohui WU, Kono N, Watanabe H, Takahashi T. Microstructure and mechanical properties of $\mathrm{SiCw}-\mathrm{Al}_{2} \mathrm{O}_{3} \mathrm{P} / 6061$ composites. Scripta Metall Mater 1993;28: 683-8.

[5] Devaraju A, Kumar A, Kotiveerachari B. Influence of rotational speed and reinforcements on wear and mechanical properties of aluminum hybrid composites via friction stir processing. Mater Des 2013;45:576-85. 
[6] Baradeswaran A, Vettivel SC, ElayaPerumal A, Selvakumar N, Franklin Issac R. Experimental investigation on mechanical behaviour, modelling and optimization of wear parameters of $\mathrm{B} 4 \mathrm{C}$ and graphite reinforced aluminium hybrid composites. Mater Des 2014;63:620-32.

[7] Wang T, Shozaki M, Yamamoto M, Kagawa A. Synergy effect of reinforcemen particle, fiber and matrix on wear resistance of hybrid metal matrix composite fabricated by low pressure infiltration process. Mater Des 2015;66:498-503. Part B.

[8] Gui M, Kang SB. Aluminum hybrid composite coatings containing SiC and graphite particles by plasma spraying. Mater Lett 2001;51:396-401.

[9] Umanath K, Palanikumar K, Selvamani ST. Analysis of dry sliding wear behaviour of Al6061/SiC/Al2O3 hybrid metal matrix composites. Compos B Eng 2013;53:159-68.

[10] Hu J, Wu G, Zhang Q, Gou H. Mechanical properties and damping capacity of $\mathrm{SiCp} / \mathrm{TiNif} / \mathrm{Al}$ composite with different volume fraction of SiC particle. Compos B Eng 2014;66:400-6.

[11] Bowen CR, Perry A, Lewis ACF, Kara H. Processing and properties of porous piezoelectric materials with high hydrostatic figures of merit. J Eur Ceram Soc 2004;24:541-5.

[12] Hu Z, Ma B, Liu S, Narayanan M, Balachandran U. Relaxor behavior and energy storage performance of ferroelectric PLZT thin films with different $\mathrm{Zr} / \mathrm{Ti}$ ratios. Ceram Int 2014;40:557-62.

[13] Gao P, Britson J, Nelson CT, Jokisaari JR, Duan C, Trassin M, et al. Ferroelastic domain switching dynamics under electrical and mechanical excitations. Nat Commun 2014:5.

[14] Hori M, Aoki T, Ohira Y, Yano S. New type of mechanical damping composites composed of piezoelectric ceramics, carbon black and epoxy resin. Compos A Appl Sci Manuf 2001;32:287-90.

[15] Tian S, Cui F, Wang X. New type of piezo-damping epoxy-matrix composites with multi-walled carbon nanotubes and lead zirconate titanate. Mater Lett 2008;62:3859-61.
[16] Yoshida I, Yokosuka M, Monma D, Ono T, Sakurai M. Damping properties of metal-piezoelectric composites. J Alloy Compd 2003;355:136-41.

[17] Poquette BD, Asare TA, Schultz JP, Brown DW, Kampe SL. Domain reorientation as a damping mechanism in ferroelastic-reinforced metal matrix composites. Metall Mater Trans A 2011;42:2833-42.

[18] Fan G-l, Li Z-q, Zhang D. Damping capacity of BaTiO3/Al composites fabricated by hot extrusion. Trans Nonferr Metals Soc China 2012;22:2512-6.

[19] Cerqueira M, Nasar RS, Leite ER, Longo E, Varela JA. Sintering and characterization of PLZT (9/65/35). Ceram Int 2000;26:231-6.

[20] McDanels D. Analysis of stress-strain, fracture, and ductility behaviour of aluminum matrix composites containing discontinuous silicon carbide reinforcement. MTA 1985;16:1105-15.

[21] MacAskill IA, Hexemer Jr RL, Donaldson IW, Bishop DP. Effects of magnesium, tin and nitrogen on the sintering response of aluminum powder. J Mater Process Technol 2010;210:2252-60.

[22] Zhang J, Perez RJ, Lavernia EJ. Documentation of damping capacity of metallic, ceramic and metal-matrix composite materials. J Mater Sci 1993;28: 2395-404.

[23] Prasad DS, Shoba C, Ramanaiah N. Investigations on mechanical properties of aluminum hybrid composites. J Mater Res Technol 2014;3:79-85.

[24] Mondolfo LF. Aluminium alloys: structures and properties. LondonBoston: Butterworths; 1976. p. 352-4.

[25] Zeng T, Dong X, Yang H, Mao C, Chen H. Enhancement of mechanical and dielectric breakdown properties by diffusion of SiC into lead zirconate titanate ceramics. Scripta Mater 2006;55:923-6.

[26] Lu H, Wang X, Zhang T, Cheng Z, Fang Q. Design, fabrication, and properties of high damping metal matrix composites - a review. Materials 2009;2:958-77.

[27] Lavernia EJ, Perez RJ, Zhang J. Damping behaviour of discontinuously reinforced al alloy metal-matrix composites. MMTA 1995;26:2803-18. 